ORIGINAL ARTICLE

\title{
Risk of tuberculin conversion among healthcare workers and the adoption of preventive measures
}

\author{
lacopo Baussano, Massimiliano Bugiani, Aurelia Carosso, Dario Mairano, Anna Pia Barocelli, \\ Marina Tagna, Vincenza Cascio, Pavilio Piccioni, Walter Arossa
}

See end of article for authors' affiliations

Correspondence to: Dr I Baussano, Cancer Epidemiology Unit, Università di Torino, Via Santena 7, 10126 Torino, Italy; iacopo.baussano@ cpo.it

Accepted 1 August 2006

Published Online First

15 August 2006

Background: In industrialised countries, occupational tuberculosis among healthcare workers (HCWs) is reemerging as an important public health issue. To prevent and control tuberculosis transmission, several institutions have issued and implemented recommendations and practice guidelines.

Objectives: To estimate the annual rate of tuberculosis infection (ARTI; per 100 person-years) among HCWs in Turin, the capital of the Piedmont region of Italy, to identify factors associated with variations in the ARTI and to evaluate the efficacy of the regional guidelines to prevent and control tuberculosis.

Methods: The study was conducted between 1997 and 2004 on a cohort of HCWs. The tuberculosis infection was diagnosed through tuberculin skin testing (TST) conversion and defined as an induration increase of at least $10 \mathrm{~mm}$ from a previous negative TST. The ARTI and the hazard ratio for each at-risk subgroup, categorised according to working activities and settings, was estimated using exponential survival models. The efficacy of the regional guidelines was estimated by stratifying the analysis according to the moment of the implementation of the guidelines (before/after).

Results: The 2182 study participants were drawn from the dynamic cohort. The overall adjusted ARTI was 1.6 (95\% Cl: 1.3 to 1.9)/100 person-years. Different workplaces (eg, administrative and infectious diseases inpatient services) and occupations (eg, clerical and medical workers) were associated with significantly different ARTIs, ranging between 0.62 and 2.62 and between 0.61 and 1.71 , respectively, whereas the TST conversion risk differed by about $16-68 \%$ and $30-60 \%$, respectively. The implementation of the guidelines coincided with overall ARTI reductions of $1.3 / 100$ person-years, and concurrently the variations between ARTls of different occupations and workplaces disappeared.

Conclusions: The occupational risk categories for targeting the surveillance and prevention of tuberculosis transmission among HCWs were identified, and the introduction of preventive measures was observed to be effective in decreasing the overall risk of tuberculosis infection among HCWs.

a industrialised countries, the current view of tuberculosis as an occupational hazard emerged only in the 1950s. Before this date, effective control interventions were not implemented, and the risk of tuberculosis among healthcare workers (HCWs) was high. The introduction of control and preventive measures against tuberculosis transmission, the advent of an effective treatment for tuberculosis and the concurrent longterm downward trends of tuberculosis incidence substantially decreased the occupational risk among HCWs. ${ }^{1}$ Currently, in industrialised countries, occupational tuberculosis among HCWs is re-emerging as an important public health issue, both because of the resurgence of the tuberculosis epidemic and the emergence of multidrug-resistant strains of mycobacteria. ${ }^{2}$ The resurgence of tuberculosis in countries with low incidence is likely to increase the risk of nosocomial transmission of Mycobacterium tuberculosis, owing to the lack of adequate awareness and updated knowledge among HCWs, particularly when tuberculosis is not recognised, diagnosis is delayed, or preventive measures and technologies are not adopted. ${ }^{2}$ Therefore, considerable efforts have been made in several countries specifically to design and promote measures for the prevention and control of $M$ tuberculosis transmission in both the community and in healthcare facilities..$^{3-6}$ The full implementation of infection control measures for tuberculosis has been reported to markedly decrease rates of tuberculosis infection among HCWs both in high-income and in low-income countries. ${ }^{78}$

Piedmont is a highly industrialised region of Italy, which is experiencing a resurgence in tuberculosis. ${ }^{9}{ }^{10}$ The tuberculosis incidence trends are particularly worrying in Turin, the capital of the Piedmont region, ${ }^{11}$ as they mirror what is happening in other comparable metropolitan areas in Europe, such as Rotterdam and London. ${ }^{12}{ }^{13}$ In 2000, the public health authorities of Piedmont issued guidelines to prevent and control the transmission of tuberculosis ${ }^{6}$ both in the community and in healthcare facilities.

Few studies have been published ${ }^{14}{ }^{15}$ on nosocomial transmission of $M$ tuberculosis in Italy and most of these papers have focused on the role of HIV in the transmission process. ${ }^{16}{ }^{17}$ Routine data on the occupational transmission of tuberculosis are lacking, although notification procedures recommend that the professional activities of tuberculosis cases should be recorded on the notification schedule. This study aimed to estimate the sex-adjusted and age-adjusted annual rate of tuberculosis infection (ARTI) among HCWs in Turin between 1998 and 2004, as indicated by tuberculin skin testing (TST) conversions, to identify factors associated with pronounced variations in the ARTI and to investigate ARTI modification related to the introduction of more stringent occupational control measures in the year $2000 .^{6}$

\section{MATERIALS AND METHODS}

According to the 14th national census, 865263 people were living in Turin in 2001, ${ }^{18} 19$ and the overall estimated incidence of tuberculosis in the same urban area in that year was 32.1

Abbreviations: ARTI, annual rate of tuberculosis infection; $B C G$, bacille Calmette-Guérin; HCW, healthcare worker; TST, tuberculin skin testing 
cases/100 000 population. About $97.5 \%$ of all tuberculosis cases attended local healthcare facilities, where they were identified, treated, and notified to the regional and national public health authorities. ${ }^{11}$ Consequently, the personnel working in the healthcare facilities of Turin were exposed to a considerable risk of $M$ tuberculosis transmission.

The participants in this study were drawn from the dynamic cohort of HCWs of Turin, between 1997 and 2004, in the framework of a health surveillance programme. The surveillance programme dealt with all personnel working (full-time or part-time), studying (medical students and specialising doctors) and volunteering in healthcare facilities (including both outpatient and inpatient services). The data of the personnel working, between January 1998 and December 2004, at three of the four local health units serving Turin were collected. Informed consent to data collection and analysis was obtained from all the subjects examined. Personnel with a negative TST result at baseline ( $<10 \mathrm{~mm}$ of induration) and with at least one follow-up visit were included in the study.

TST conversion was defined as an increase of at least $10 \mathrm{~mm}$ from a previous negative TST, in accordance with the American Thoracic Society and Centers for Disease Control and Prevention diagnostic standards definition. ${ }^{4}$ Piedmont's public health authorities prescribed the performance of the baseline TST at hiring and recommended, at least among presumed subjects vaccinated with bacille Calmette-Guérin (BCG) or those with a previous high risk of tuberculosis infection, the two-step baseline testing procedure to minimise the likelihood of interpreting a subsequent boosted reaction as a true conversion due to recent infection. ${ }^{6}$ TST was performed using the Mantoux technique with $0.1 \mathrm{ml}$ of purified protein derivative containing 5 TU (Biocine Sclavo, Pisa, Italy), which was injected intradermally and read $48-72 \mathrm{~h}$ after placement. TST results were measured as the diameter of induration transverse to the axis of the forearm and recorded in millimetres. ${ }^{20}$ The personnel responsible for performing and

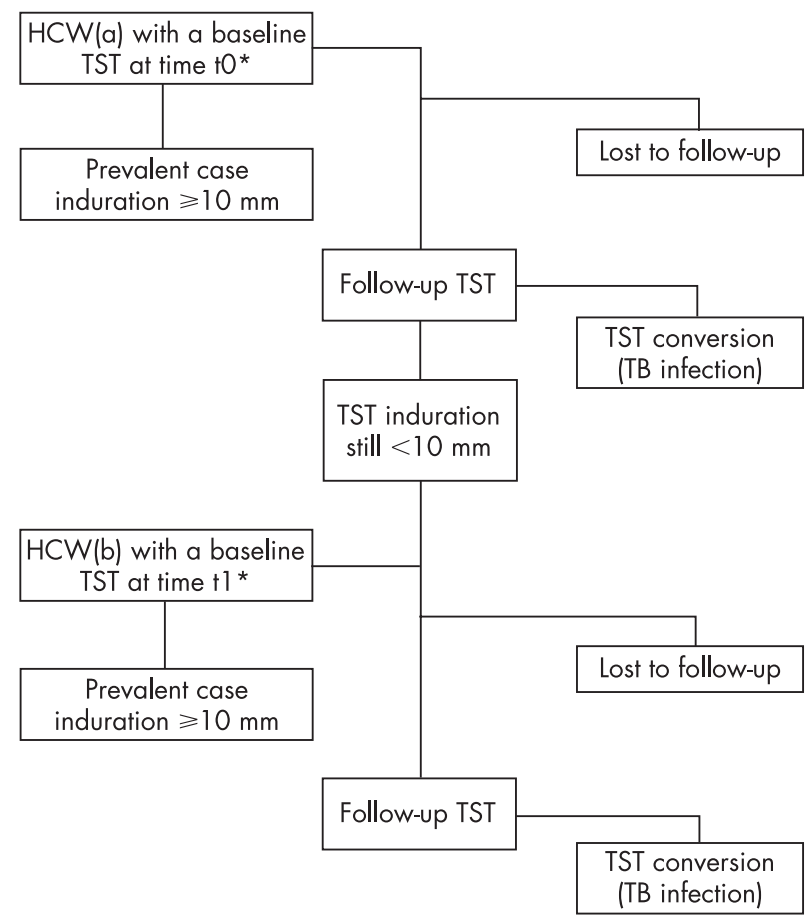

Figure 1 Selection and follow-up of healthcare workers. HCW, healthcare worker; TB, tuberculosis; TST, tuberculin skin testing. ${ }^{*}$ The selection and follow-up process has been reported for every healthcare worker. reading the TSTs were specifically trained by the medical staff of occupational services. The Mantoux skin tests were performed and read at workplaces, and self-reporting of results was not allowed.

For this study, the occupations and workplaces of the HCW were grouped as follows: clerical, nursing, medical and social workers for the work activities, and administrative, outpatient, inpatient-infectious diseases, inpatient-surgery, inpatientmedical and laboratory services (including all those services specialised in performing laboratory activities such as microbiology, mycobacteriology, pathology and chemical-physical analyses) for the workplaces.

Follow-up visits were scheduled at regular intervals between 6 months and 2 years, depending on the risk of tuberculosis transmission in the healthcare facilities, which was evaluated according to international recommendations and Italian law. ${ }^{6}$ The personnel working in administrative settings were scheduled for a follow-up visit every 2 years, whereas those working in outpatient, inpatient and laboratory services were scheduled for yearly follow-up visits. Follow-up visits at 6 months were advised as an exceptional measure, regardless of the service of activity, only in cases of potentially infectious exposure of the HCWs.

Person-time for HCWs without TST conversion was calculated as the time from the first negative until the last negative TST result. Person-time for HCWs with TST conversion was calculated as the time from the first negative TST result to the conversion, ${ }^{21}$ assuming that the likelihood of being infected with $M$ tuberculosis remained constant throughout the follow-up intervals.

Demographic and occupational data, including age, sex, BCG vaccination status, age at hiring, occupation and workplace were collected from the HCWs' occupational records. Although in our region the TST conversion rates in BCG-vaccinated subjects is $<5 \%$ using the $10 \mathrm{~mm}$ diameter, ${ }^{22}$ HCWs vaccinated with BCG $(\mathrm{n}=188$ with a TST reaction of $<10 \mathrm{~mm})$ were excluded from the analyses to minimise the potential confounding effect of previous antigenic stimulations.

To estimate the ARTI and the hazard ratio (HR) for each atrisk subgroup, the data were analysed using univariate and multivariate parametric exponential survival models. ${ }^{23}{ }^{24}$ The following covariates were separately investigated with respect to their influence on the HR for being infected with $M$ tuberculosis: age, sex, duration of employment as HCW (categorised as $<1$ and $\geqslant 1$ years), working in a hospital rather than a community setting, occupation, workplace and occurrence of at least one change of workplace or occupation during the study period. The selected multivariate exponential survival models included the following variables: age (as a continuous variable), sex, occupation and workplace. The adoption of preventive measures according to the regional guidelines was taken into account as a stratifying variable. Measures to prevent and control the transmission of tuberculosis both in hospital and community settings were developed and adopted as a result of a national debate on tuberculosis control and an effort of the local public health authorities to unify and coordinate preventive measures. In particular, in 1998, the Italian Ministry of Health issued a set of guidelines for the control of tuberculosis, ${ }^{25}$ based on recommendations proposed by the Italian Chest Physician Association (AIPO-Tuberculosis Working Group). ${ }^{26}$

Control measures were based on administrative, organisational, technical and educational interventions for HCWs and healthcare settings. They included (a) the appointment, in every healthcare facility, of a "tuberculosis official" responsible for the tuberculosis control programme; (b) the adoption of procedures to assess the risk of tuberculosis transmission; (c) 
the prompt diagnosis and isolation of cases of potentially infectious tuberculosis; (d) the adoption of respiratory protection measures, particularly while performing coughinducing procedures; (e) the regular and systematic education and training of HCWs about the prevention and control of tuberculosis transmission; (f) the introduction of a screening programme for the diagnosis of active tuberculosis and latent tuberculosis infection; and finally $(\mathrm{g})$ the implementation of containment measures (Bio-Hazard Type III) in mycobacteriological laboratories. ${ }^{27}$ To account for the efficacy of the fully implemented control measures, in the data analysis, we considered the intermediary period between issuing guidelines (July 2000) and full implementation (December 2001) as not contributing to the estimate of the control measures efficacy. In principle, this conservative approach may have led to an underestimation of the efficacy of the preventive measures.

\section{STATISTICAL ANALYSIS}

The overall and stratified (before/after the implementation of regional guidelines) sex-adjusted and age-adjusted ARTIs (per 100 person-years of observation) for each occupational and workplace group were estimated from the multivariate exponential model. Statistical analyses were conducted with the STATA V.9.1 software package. ${ }^{28}$

\section{RESULTS}

During the period of time under investigation, 4601 HCWs were screened for latent tuberculosis infection; 894 (19.4\%) were prevalent cases with a positive first baseline TST $(\geqslant 10 \mathrm{~mm})$, and were not included in the cohort analysis (fig 1). Of the remaining HCWs, 1525 (33.1\%) did not have a follow-up test. The data analysis was carried out on the remaining 2182 $(47.4 \%)$ HCWs. The median age at hiring was 30 (range 18$65)$ years and two thirds of them were women $(n=1632)$. Of the HCWs, 1069 (49\%) had one follow-up TST, 625 (28.6\%) had two follow-up TSTs, 319 (14.6\%) had three follow-up TSTs, 68 (3.1\%) had four follow-up TSTs, 49 (2.2\%) had five follow-up TSTs, $30(1.4 \%)$ had six follow-up TSTs and 22 (1\%) had seven follow-up TSTs. Table 1 shows the main occupational characteristics of the HCWs included in the cohort analysis.

During the follow-up period, there were 148 episodes of TST conversion out of 8497 person-years at risk, corresponding to a crude ARTI of 1.7 (95\% confidence interval (CI) 1.48 to 2.04)

Table 1 Occupational characteristics of healthcare workers included in the cohort analysis $(n=2182)$, and distribution of tuberculin skin testing conversions $(n=148$ ) and of person-years at risk $(n=8947)$

\begin{tabular}{|c|c|c|c|}
\hline $\begin{array}{l}\text { Occupational } \\
\text { characteristics }\end{array}$ & n (\%) & $\begin{array}{l}\text { TST } \\
\text { conversions, } n\end{array}$ & $\begin{array}{l}\text { Person- } \\
\text { years at risk }\end{array}$ \\
\hline $\begin{array}{l}\text { At least one change of } \\
\text { occupation or workplace }\end{array}$ & 258 (11.8) & 10 & 712 \\
\hline Working in hospital settir & 1532 (70.2) & 117 & 6061 \\
\hline \multicolumn{4}{|c|}{ Occupation (work activity) } \\
\hline Clerical & $93(4.3)$ & 3 & 284 \\
\hline Medical & 567 (26.0) & 43 & 2200 \\
\hline Nursing & $1412(64.7)$ & 99 & 5566 \\
\hline Social & $110(5.0)$ & 3 & 447 \\
\hline \multicolumn{4}{|l|}{ Workplace } \\
\hline Laboratory & 149 (6.8) & 20 & 539 \\
\hline Administrative & $112(5.1)$ & 2 & 375 \\
\hline Outpatient & $692(31.7)$ & 38 & 2661 \\
\hline Surgery & $367(16.8)$ & 36 & 1538 \\
\hline Medicine & $748(34.3)$ & 39 & 2938 \\
\hline Infectious disease & $114(5.2)$ & 13 & 446 \\
\hline $\begin{array}{l}\text { Duration of employment } \\
(\geqslant 1 \text { years) }\end{array}$ & $2155(98.8)$ & 1 & 100 \\
\hline
\end{tabular}

per 100 person-years. Table 2 shows the results of the univariate analyses, considering the laboratory services and the nursing workers as the risk reference categories. Work activities and workplaces were associated with significant variations of the hazard of being infected with $M$ tuberculosis. HCWs operating in different workplaces showed a smaller risk of TST conversion than those working in laboratories. Social workers had a smaller risk of conversion than nurses, whereas medical workers had a slightly raised risk of TST conversion. The sex and age of HCWs, the duration of employment considered as a dichotomous variable (adopting as cut-off the first year of employment), the employment setting (hospital $v$ community) and the change of either the work setting or activity did not significantly modify the hazard of TST conversion.

Table 3 shows the results of multivariate analyses using the parametric exponential model including age, occupations, workplaces and sex. Similar to the univariate model, the sex of the HCW did not have any significant effect on the hazard of TST conversion (adjusted HR 0.99 (95\% CI 0.8 to 1.2)). The workplaces were significantly associated with modification of the hazard of infection with $M$ tuberculosis. More specifically, considering medicine services as the risk reference category, the hazard for TST conversion significantly increased in surgery (HR 1.59), infectious diseases (HR 1.94) and laboratory services (HR 2.84). On the other hand, personnel working in outpatient services did not show any significant variation of the risk of tuberculosis infection from those working in medicine services. Estimates drawn for personnel working in administrative services were too unreliable to draw any significant comparison. Similarly, considering the nursing workers as the risk reference category, for medical workers the hazard of TST conversion was reduced by about $16 \%$, whereas for the social workers it was reduced by about $68 \%$. Finally, the age of the HCWs was slightly associated with a raised risk of TST conversion ( $3 \%$ per year of age).

Table 2 Univariate analysis of risk factors for Mycobacterium tuberculosis infection, according to the selected definition of latent tuberculosis infection and tuberculin skin testing conversion

\begin{tabular}{|c|c|c|}
\hline Variable & $\begin{array}{l}\text { TST conversion } \\
\text { HR }(95 \% \mathrm{Cl})\end{array}$ & p Value \\
\hline \multicolumn{3}{|l|}{ Sex } \\
\hline Women* & 1 & \\
\hline Men & $1.02(0.94$ to 1.11$)$ & 0.64 \\
\hline \multicolumn{3}{|c|}{ Duration of employment (years) } \\
\hline$<1^{*}$ & 1 & \\
\hline$\geqslant 1$ & $2.24(0.14$ to 34.98$)$ & 0.564 \\
\hline \multicolumn{3}{|l|}{ Work setting } \\
\hline Community* & 1 & \\
\hline Hospital & $1.35(0.93$ to 1.96$)$ & 0.114 \\
\hline \multicolumn{3}{|l|}{ Workplace } \\
\hline Laboratory* & 1 & \\
\hline Administrative & $0.19(0.04$ to 0.83$)$ & 0.027 \\
\hline Outpatient & $0.45(0.32$ to 0.63$)$ & 0.000 \\
\hline Surgery & $0.68(0.50$ to 0.94$)$ & 0.020 \\
\hline Medicine & $0.42(0.32$ to 0.54$)$ & 0.000 \\
\hline Infectious diseases & 0.79 (0.67 to 0.93$)$ & 0.005 \\
\hline \multicolumn{3}{|c|}{ Occupation (work activity) } \\
\hline Nursing workers* & 1 & \\
\hline Clerical workers & $0.67(0.36$ to 1.25$)$ & 0.208 \\
\hline Medical workers & $1.10(1.02$ to 1.17$)$ & 0.011 \\
\hline Social workers & $0.42(0.25$ to 0.70$)$ & 0.000 \\
\hline \multicolumn{3}{|c|}{ Change of occupation or setting } \\
\hline No* & 1 & \\
\hline Yes & $0.86(0.34$ to 2.19$)$ & 0.753 \\
\hline Age (years) & $1.02(1.00$ to 1.05$)$ & 0.074 \\
\hline
\end{tabular}

TST, tuberculin skin testing. *Reference category. 
Table 4 shows the adjusted ARTI estimated using the multivariate exponential model for occupations and workplaces. The overall adjusted ARTI was 1.6 (95\% CI 1.3 to 1.9 )/ 100 person-years, ranging between 0.61 and 3.42/100 personyears for the social and laboratory workers, respectively. The estimated ARTI for personnel working in administration was the least accurate $(0.6$ (95\% CI 0.1 to 3.4$) / 100$ person-years), given the small number of episodes of conversion $(n=2)$ among this group of workers.

After the implementation of regional guidelines to prevent and control the transmission of tuberculosis among HCWs, the ARTI were reduced both in absolute and in relative terms. Overall, before 2002, about 106 infections were counted over 4034 person-years, whereas after this date only 42 infections were observed over 4463 person-years of observation. The overall ARTI reduction was $1.3 / 100$ person-years. The largest ARTI reduction occurred among medical workers and those working in laboratories, with a reduction rate of 1.6 and 2.5/100 personyears, respectively. Overall, there was a chronological consistency between the disappearance of conversion rate differences existing between occupationally defined groups (by workplace and working activity) and the implementation of the guidelines.

\section{DISCUSSION}

This study shows an interesting association between job-related categories (occupation and workplace) and the risk of TST conversion. This is not a constant finding in the literature, ${ }^{829-31}$ and doubts ${ }^{21} 32$ still remain as to the role of each specific work activity and location, possibly because the characteristics of the occupations and workplaces can vary widely and may be influenced by the local organisation of the healthcare facilities. However, studies in industrialised countries have shown annual TST conversion rates ranging from $0.1 \%$ to $2 \%$ among unexposed personnel and from $1 \%$ to $10 \%$ among highly exposed HCWs. ${ }^{73}$

The simultaneous investigation of the risk associated with workplaces and occupations has shown that the classification adopted is helpful for differentiating among several risk categories. Workplaces can be grouped into four clusters: administrative services (minimum risk), outpatient and inpatient medical services (very limited risk), inpatient infectious diseases and surgery services (limited risk), and laboratory services (medium risk). Occupational categories can be differentiated between social, medical and nursing activities.

Table 3 Multivariate analysis (parametric exponential model) of risk factors for Mycobacterium tuberculosis infection, according to the selected definition of latent tuberculosis infection and tuberculin skin testing conversion

\begin{tabular}{lll}
\hline Covariates & HR $(95 \%$ Cl) & p Value \\
\hline $\begin{array}{l}\text { Sex } \\
\text { Women* }\end{array}$ & 1 & \\
$\quad$ Men & $0.99(0.84$ to 1.17$)$ & 0.925 \\
Workplace & 1 & \\
$\quad$ Medicine * & $0.43(0.03$ to 6.42$)$ & 0.544 \\
$\quad$ Administrative & $1.10(0.77$ to 1.59$)$ & 0.594 \\
$\quad$ Outpatient & $1.59(1.14$ to 2.22$)$ & 0.006 \\
$\quad$ Surgery & $1.94(1.50$ to 2.49$)$ & 0.000 \\
Infectious diseases & $2.84(2.23$ to 3.62$)$ & 0.000 \\
$\quad$ Laboratory & 1 & \\
Occupation (work activity) & $1.08(0.17$ to 6.74$)$ & 0.934 \\
$\quad$ Nursing workers* & $0.84(0.75$ to 0.93$)$ & 0.001 \\
$\quad$ Clerical workers & $0.32(0.17$ to 0.62$)$ & 0.001 \\
$\quad$ Medical workers & $1.03(1.00$ to 1.05$)$ & 0.046 \\
$\quad$ Social workers & & \\
Age (years) & & \\
\hline *Reference category. & & \\
\hline
\end{tabular}

The fact that nurses are more often involved in performing cough-inducing procedures and that they normally spend more time in close contact with patients may well explain the raised risk of tuberculosis infection compared with medical workers. The potential distortion of the estimate of the annual rate of tuberculosis infection consequent to different intervals between the visits, according to the work service, might have influenced only the estimate among administrative personnel. However, administrative workers are plausibly expected to be exposed to the general population risk of tuberculosis infection, therefore the bias introduced would marginally affect the conclusions of this study.

The role of age in influencing the TST conversion risk is controversial. In this study, the influence of age on the risk of tuberculosis infection was minimal. Some studies uncovered a significant positive association between age and TST conversion, ${ }^{29} 3034$ whereas others did not confirm this association. $^{8} 213135$ However, data from a rural African population have shown that an apparent increase in the risk of tuberculosis infection associated with age can arise as a statistical artefact due to the imperfect repeatability of the tuberculin test. ${ }^{36}$

To minimise the possible risk of misclassification of TST conversion due to environmental mycobacteria infection or undetected BCG vaccination, we adopted the most specific criterion for defining TST conversion ${ }^{37}$ and excluded BCGvaccinated HCWs from the analysis. Finally, according to the data available on local exposure to environmental mycobacteria, these agents seem to have only a minor role in determining local TST conversions in the Turin area. ${ }^{11}{ }^{22}$

Some authors have found that a shorter duration of employment was a risk factor for TST conversion, possibly because less experienced HCWs were less aware of the risk of nosocomial tuberculosis transmission and prevention..$^{78}$ This study failed to confirm this finding. In addition, changes in occupation or workplace were investigated as potential risk factors for conversion, as moving from one service to another or switching to a different work activity may in principle be related to skilfulness, risk awareness and previous exposure to nosocomial infectious risks. However, this factor was not significantly associated with the risk of TST conversion, probably because of a low mobility rate in the different risk settings.

The second important outcome of this study is that the introduction of preventive measures was effective in decreasing the overall risk of tuberculosis infection among HCWs. Several studies in high-income countries have investigated the efficacy of control measures in preventing nosocomial transmission of tuberculosis, although they were mostly focused on the transmission of multidrug-resistant mycobacteria. ${ }^{38}{ }^{39}$ Yanai et $a l^{8}$ in Thailand investigated the efficacy of control measures in a more general context of nosocomial transmission. They concluded that most of the reduction of nosocomial transmission of tuberculosis could be reasonably attributed to the implementation of administrative control measures. Blumberg et al prospectively investigated the TST conversion rates among house staff in a hospital in Atlanta (Georgia, USA) after implementing the tuberculosis infection control measures. They also concluded that TST conversion rates decreased significantly after the implementation of infection control measures. In this study, the conversion rate differences between occupationally defined groups (by workplace and work activity), existing before the guidelines, disappeared after the year the guidelines were implemented (table 4). As no further studies were performed to selectively ascertain which preventive measures were implemented, it was not possible to definitely evaluate their specific effect on ARTI reduction. However, there is indirect evidence of the efficacy of guideline 
Table 4 Age-adjusted and sex-adjusted estimated annual rate of tuberculosis infection $195 \%$ Cl) per 100 person-years (\%), overall, before and after the implementation of the regional guidelines

\begin{tabular}{|c|c|c|c|}
\hline \multirow{2}{*}{$\begin{array}{l}\text { Work activities } \\
\text { and sites }\end{array}$} & \multirow[b]{2}{*}{ Overall (\%) } & \multicolumn{2}{|c|}{ Implementation of the regional guidelines } \\
\hline & & Before (\%) & After (\%) \\
\hline \multicolumn{4}{|l|}{ Occupation (work activity) } \\
\hline Social workers & $0.61(0.25-1.50)$ & $0.91(0.43-1.91)$ & $0.30(0.09-1.01)$ \\
\hline Clerical workers & $0.99(0.57-1.74)$ & $1.33(0.76-2.33)$ & $0.50(0.25-1.00)$ \\
\hline Medical workers & $1.71(1.43-2.04)$ & $2.46(2.11-2.87)$ & $0.89(0.59-1.37)$ \\
\hline Nursing workers & $1.67(1.51-1.86)$ & $2.34(2.05-2.68)$ & $0.92(0.64-1.31)$ \\
\hline \multicolumn{4}{|l|}{ Workplace } \\
\hline Administrative services & $0.62(0.11-3.39)$ & $0.85(0.19-3.90)$ & $0.31(0.04-2.55)$ \\
\hline Outpatient services & $1.40(1.34-1.47)$ & $1.94(1.62-2.32)$ & $0.78(0.57-1.08)$ \\
\hline Medicine services & $1.29(0.94-1.77)$ & $1.85(1.29-2.64)$ & $0.74(0.48-1.14)$ \\
\hline Infectious disease services & $2.62(2.42-2.83)$ & $3.57(3.10-4.12)$ & $1.33(0.95-1.88)$ \\
\hline Surgery services & $2.22(2.12-2.33)$ & $3.07(2.57-3.66)$ & $1.20(0.91-1.59)$ \\
\hline Laboratory services & $3.42(2.59-4.51)$ & $4.22(3.35-5.30)$ & $1.70(0.96-3.02)$ \\
\hline Overall & $1.56(1.30-1.87)$ & $2.19(1.81-2.56)$ & $0.84(0.55-1.28)$ \\
\hline
\end{tabular}

implementation in reducing ARTI among HCWs. Firstly, during the same period of time and in the same urban area, the incidence of tuberculosis among the general population remained constant. ${ }^{10}$ The observed ARTI reduction among HCWs can therefore be reasonably attributed to the interventions carried out in the healthcare sector rather than to a widespread decline in the risk of tuberculosis infection among the general population. Secondly, the general ARTI reduction affected the different HCWs groups in different ways: the greatest rate reductions occurred among those workers with the highest TST conversion rates before the implementation of the guidelines. In particular, the annual rate reduction was larger among personnel working in laboratories and infectious disease units. Personnel working in laboratories are constantly exposed to hazardous biological samples collected to identify and isolate mycobacteria, while those working in infectious disease units are routinely exposed to infectious tuberculosis cases. A relevant reduction in the annual rate has also been observed among personnel working in surgery units, where potentially hazardous invasive procedures are performed to collect biological samples for a definite diagnosis of tuberculosis. Therefore, the systematic improvement of the precautions adopted to prevent tuberculosis transmission among those groups of HCWs resulted in a large reduction in the risk of infection and the levelling off of ARTI towards a lower baseline.

The lack of information on socioeconomic and migrant status of HCWs is not likely to have significantly biased the conclusions of this study. In Italy, there are no extreme differences of socioeconomic status and lifestyle among HCWs, as reported elsewhere in high-income countries ${ }^{21}$; furthermore, in Turin, the number of immigrant HCWs remains negligible, although it is steadily increasing, therefore both factors can be reasonably ruled out as potential confounders of the study results.

In conclusion, this study suggests that the introduction of the preventive measures prescribed in the regional guidelines was successful in effectively decreasing the overall risk of tuberculosis infection among HCWs.

\section{ACKNOWLEDGEMENTS}

We thank the personnel of the Local Health Units 2, 3 and 4 of Turin, who contributed to this investigation and Susan Phillips, English reader, Turin University, for the language revision.

\section{Authors' affiliations \\ lacopo Baussano, Cancer Epidemiology Unit, CPO Piemonte, CeRMS, University of Turin, Turin, Italy}

Massimiliano Bugiani, Aurelia Carosso, Pavilio Piccioni, Walter Arossa, CPA ASL 4, Regional Reference Centre for Tuberculosis Prevention, Turin, Italy

Dario Mairano, Occupational Medicine, ASL 4, Turin, Italy

Anna Pia Barocelli, Marina Tagna, Occupational Medicine, ASL 3, Turin, Italy

Vincenza Cascio, Occupational Medicine, ASL 2, Turin, Italy

Funding: This study was performed with the grants of Regione Piemonte Italy, Assessorato Sanità, Progetti di Ricerca Sanitaria Finalizzata, 2003. The method applied in this study was developed in the framework of the projects supported by the Compagnia San Paolo-FIRMS.

Competing interests: None.

\section{REFERENCES}

1 Sepkowitz KA. Tuberculosis and the health care worker: a historical perspective. Ann Intern Med 1994; 120:71-9.

2 Menzies D, Fanning A, Yuan L, et al. Tuberculosis among health care workers. N Engl J Med 1995;332:92-8.

3 Canadian Lung Association. Canadian tuberculosis standards, 5th edn. Ottawa: Government of Canada, 2000.

4 Jensen PA, Lambert LA, lademarco MF, et al. Guidelines for preventing the transmission of Mycobacterium tuberculosis in health-care settings, 2005. MMWR Recomm Rep 2005;54:1-141.

5 Joint Tuberculosis Committee of the British Thoracic Society. Control and prevention of tuberculosis in the United Kingdom: code of practice 2000. Thorax 2000;55:887-901.

6 Assessorato Sanità - Assistenza. Prevenzione e il controllo della tubercolosi umana in Piemonte -Protocolli operativi. Torino: Direzione Sanità Pubblica, Settore Igiene e Sanità Pubblica, Regione Piemonte, 2000.

7 Blumberg HM, Sotir M, Erwin M, et al. Risk of house staff tuberculin skin test conversion in an area with a high incidence of tuberculosis. Clin Infect Dis 1998;27:826-33.

8 Yanai $\mathrm{H}$, Limpakarnjanarat K, Uthaivoravit W, et al. Risk of Mycobacterium tuberculosis infection and disease among health care workers, Chiang Rai, Thailand. Int J Tuberc Lung Dis 2003;7:36-45.

9 Matteelli A, Casalini C, Raviglione MC, et al. Supervised preventive therapy for latent tuberculosis infection in illegal immigrants in Italy. Am J Respir Crit Care Med 2000;162:1653-5.

10 Faggiano F, Vigna-Taglianti FD, Versino E, et al. Tuberculosis incidence in Turin, Italy, 1973-1999. Int J Tuberc Lung Dis 2004;8:171-9.

11 Baussano I, Bugiani M, Gregori D, et al. Undetected burden of tuberculosis in a low-prevalence area. Int J Tuberc Lung Dis 2006;10:415-21.

12 KNVC. Index tubercolosis 2000. The Hague, The Netherlands: Tuberculosis Foundation, 2003.

13 Mohammad A, Clare F, Delphine A. Annual report on tuberculosis cases reported in 2001 in England, Wales and Northern Ireland. London: Tuberculosis Section, Communicable Disease Surveillance Centre, Health Protection Agency, 2004.

14 Franchi A, Banfi MB, Franco G. Effectiveness of interventions for the control and prevention of tuberculosis in health care facilities: a review of ATS, CDC, OSHA recommendations. Med Lav 2003;94:506-20.

15 Franchi A, Garavini D, Bisio S, et al. Health surveillance program for the prevention of Mycobacterium tuberculosis infection risk among health personnel of the Polyclinic and the University of Modena. G Ital Med Lav Ergon 1999;21:122-9. 
16 Di Perri G, Cadeo GP, Castelli F, et al. Transmission of HIV-associated tuberculosis to healthcare workers. Infect Control Hosp Epidemiol 1993; 14:67-72.

17 Di Perri G, Cruciani M, Danzi MC, et al. Nosocomial epidemic of active tuberculosis among HIV-infected patients. Lancet 1989:2:1502-4.

18 Decreto Del Presidente Del Consiglio Dei Ministri. Popolazione legale della Repubblica in base al censimento del 21 ottobre 2001. Gazz Ufficiale Ser Gen, 2003;N., 81

19 Prefettura di Torino-Ufficio di statistica. Osservatorio Interistituzionale sugli Stranieri in Provincia di Torino. Torino: Comune di Torino, 2002.

20 ATS/CDC. Targeted tuberculin testing and treatment of latent tuberculosis infection. Am J Respir Crit Care Med 2000;161:S221-47.

21 Panlilio AL, Burwen DR, Curtis $A B$, et al. Tuberculin skin testing surveillance of health care personnel. Clin Infect Dis 2002:35:219-27.

22 Bugiani M, Borraccino A, Migliore E, et al. Tuberculin reactivity in adult BCG vaccinated subjects: a cross-sectional study. Int J Tuberc Lung Dis 2003;7:320-6.

23 Bradburn MJ, Clark TG, Love SB, et al. Survival analysis part II: multivariate data analysis - an introduction to concepts and methods. $\mathrm{Br} J$ Cancer 2003:89:431-6.

24 Bradburn MJ, Clark TG, Love SB, et al. Survival analysis part III: multivariate data analysis - choosing a model and assessing its adequacy and fit. $\mathrm{Br} J$ Cancer 2003;89:605-11

25 Linee guida 17/12/1998. Su proposta del Ministro della Sanità, ai sensi dell'art. 115 , comma 1, lettera b, del decreto legislativo 31 marzo 1998, n 112.

26 Bugiani M, Aipo-Tubercolosi GD. Proposed protocol for the prevention of tuberculosis transmission among health workers. Application to the DLGS 626/ 94 and successive modifications. AIPO-Tuberculosis Working Group. Med Lav 1997:88:237-49.

27 Centers for Disease Control and Prevention. Guidelines for preventing the transmission of Mycobacterium tuberculosis in health-care facilities. MMWR Recomm Rep 1994;43:1-132.
28 Cleves M, Gould W, Gutierrez RG. An introduction to survival analysis using Stata. College Station: Stata Press, 2002.

29 Louther J, Rivera P, Feldman J, et al. Risk of tuberculin conversion according to occupation among health care workers at a New York City hospital. Am J Respir Crit Care Med 1997;156:201-5.

30 Schwartzman K, Loo V, Pasztor J, et al. Tuberculosis infection among health care workers in Montreal. Am J Respir Crit Care Med 1996;154:1006-12.

31 Kraut A, Coodin M, Plessis R, et al. Predictors of positive tuberculin skin test (TST) results after 2-step TST among health care workers in Manitoba, Canada. Clin Infect Dis 2004;39:e113-18.

32 Srour-Fihmi S, Weiler-Ravell D, Kitzes R, et al. Routine two-step skin testing for tuberculosis in the staff of a geriatric hospital in Israel: booster and conversion rates. J Hosp Infect 2000;46:141-6.

33 Bonifacio N, Saito M, Gilman RH, et al. High risk for tuberculosis in hospital physicians, Peru. Emerg Infect Dis 2002;8:747-8.

34 Moreno S, Blazquez R, Novoa A, et al. The effect of BCG vaccination on tuberculin reactivity and the booster effect among hospital employees. Arch Intern Med 2001;161:1760-5.

35 Alonso-Echanove J, Granich RM, Laszlo A, et al. Occupational transmission of Mycobacterium tuberculosis to health care workers in a university hospital in Lima, Peru. Clin Infect Dis 2001;33:589-96.

36 Fine PE, Bruce J, Ponnighaus JM, et al. Tuberculin sensitivity: conversions and reversions in a rural African population. Int J Tuberc Lung Dis 1999;3:962-75.

37 Menzies D. Interpretation of repeated tuberculin tests. Boosting, conversion, and reversion. Am J Respir Crit Care Med 1999;159:15-21.

38 Wenger PN, Otten J, Breeden A, et al. Control of nosocomial transmission of multidrug-resistant Mycobacterium tuberculosis among healthcare workers and HIV-infected patients. Lancet 1995;345:235-40.

39 Maloney SA, Pearson ML, Gordon MT, et al. Efficacy of control measures in preventing nosocomial transmission of multidrug-resistant tuberculosis to patients and health care workers. Ann Intern Med 1995; 122:90-5.

\section{International Forum on Quality \& Safety in Health Care}

18-20 April 2007

Palau de Congressos, Barcelona

\section{Registration now open}

- Book by 23 February 2007 and save up to $£ 60$ on the 3-day delegate fee

- Join us at the premier international event for those dedicated to improving quality and safety in health care

- Speakers include: Donald Berwick, Sir John Oldham, Lucien Leape, Richard Smith, Helen Bevan, Lloyd Provost and Rosa Sunol

- For more information and to book online please visit: www.quality.bmipg.com 